Nota de investigación

\title{
Germinación de orquídeas utilizando un método sencillo y económico, reproducible en ambientes no óptimos
}

\author{
Citlalli Harris Valle ${ }^{\S}$ \\ Itzel Landero Benavidez \\ José Francisco Alvarado Vázquez \\ René Hernández Gómez \\ ${ }^{1}$ Instituto Tecnológico Superior de Zacapoaxtla. Carretera Acuaco-Zacapoaxtla km 8, Col. Totoltepec, \\ Zacapoaxtla, Puebla, México. CP. 73680. (itzi22.ilb@gmail.com; ialvarado972fra@gmail.com; \\ hdzrene@hotmail.com). \\ §Autora para correspondencia: citlalliharris@yahoo.com.mx.
}

\section{Resumen}

El cultivo de orquídeas es complicado por la baja tasa de germinación de las semillas, así como por las dificultades en la sobrevivencia y el establecimiento de las plantas. Se sabe que estas plantas requieren estar asociados con hongos endófitos (colonizan las raíces y facilitan los procesos de nutrición de las plantas). Lo anterior, origina que las personas dedicadas al comercio de orquídeas como plantas ornamentales, extraigan de forma ilegal ejemplares silvestres de bosques conservados. En este trabajo se propone una estrategia de germinación de orquídeas utilizando elementos económicos y accesibles, que puede realizarse en lugares sin infraestructura de laboratorio. Los elementos básicos son frascos de vidrio transparente, un soporte de cartón, agua y un cajón adaptado para mantener un ambiente estéril. La estrategia es funcional en cuanto a su viabilidad para desarrollarse en ambientes no óptimos para este tipo de trabajos, se obtuvieron semillas germinadas, pero es necesario determinar el momento propicio y encontrar una forma de extraer las semillas germinadas de los frascos y colocarlas en sustratos que permitan su establecimiento y desarrollo. La cantidad de semillas germinadas es baja, no obstante, se considera que servirá de base para que personas no especializadas puedan propagar orquídeas en sus localidades desde la etapa de germinación.

Palabras clave: plantas ornamentales, procedimiento económico, reproducción.

Recibido: mayo de 2021

Aceptado: junio de 2021 
La propagación de orquídeas es complicada debido a las características propias de este grupo de plantas. Está documentado que su germinación depende de las condiciones ambientales en las que se encuentre la semilla, de la tasa de fecundación y de la presencia del microorganismo simbiontes (Arditi et al., 2000; Karol et al., 2015). Asimismo, el establecimiento de las plántulas y su desarrollo hasta individuos adultos, es complicado en especímenes epífitos (Damon, 2003).

Existen algunas estrategias de reproducción de orquídeas; no obstante, los métodos más exitosos son costosos por los requerimientos (condiciones de desarrollo, medios de cultivo in vitro, uso de fitohormonas, equipos, etc.) y se necesita infraestructura especial (Suzuki et al., 2012; Pradhan et al., 2016). Debido a lo anterior, es común que las personas dedicadas al comercio de orquídeas como plantas ornamentales extraigan ejemplares de bosques conservados, generalmente la extracción es ilegal ocasionando que las poblaciones silvestres se dañen, incluso algunas especies ya estan en alguna categoría de conservación dentro de la NOM-059-2010 (Hágsater et al., 2005).

En la región nororiental poblana existen poblaciones importantes de la familia Orquidiacea, las condiciones geográficas de la región permiten que la diversidad de este tipo de plantas sea alta (Pérez Bravo et al., 2010). Adicionalmente, la vocación turística de la zona origina que los visitantes busquen y adquieran orquídeas y por lo tanto sean cotizadas a buen precio (EmeterioLara et al., 2016). Es complicado contrarrestar o eliminar la comercialización de ejemplares ilegales, debido a que constituyen una fuente de ingreso para muchas familias (Cruz et al., 2015).

Una estrategia que tienen los pobladores es propagarlas por fragmentación utilizando bulbos o esquejes; En este trabajo se estandarizó una estrategia de germinación de orquídeas mediante un método sencillo y económico, que puede ser reproducible por las personas de comunidades rurales que cuente con las condiciones climáticas adecuadas para el desarrollo de estas plantas. Se busca establecer las bases para el desarrollo de una estrategia de propagación como alternativa para las familias que se dedican al comercio de plantas ornamentales, que sea económicamente accesible.

El primer paso fue la elaboración de los sistemas de germinación utilizando frascos de vidrio transparente de 100 a $150 \mathrm{ml}$, dentro del frasco se colocaron conos de cartón de material utilizado para el transporte de huevo, se cubrió la boca del frasco con gasas estériles y se fijó con ligas (Figura 1a). Para la siembra se diseñó una cámara casera (utilizando cajas forradas internamente con aluminio) para el mantenimiento de un ambiente estéril, con velas encendidas como una forma de sustituir el uso de mecheros (Figura 1b). Los frascos se desinfectaron en baño María.
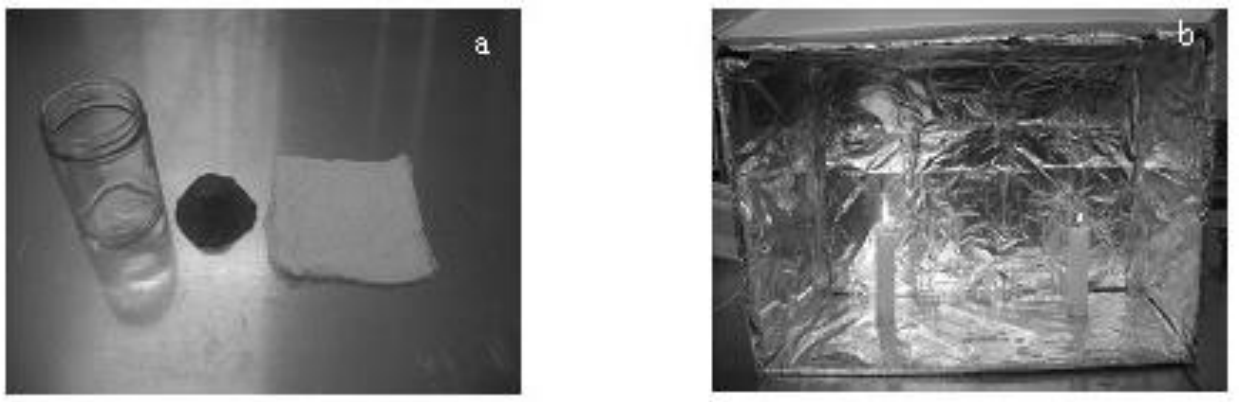

Figura 1. Materiales usados para la elaboración del recipiente que funcionó como sistema de germinación de semillas (a) y cajón que permitió mantener el ambiente estéril (b). 
La siembra de las semillas se hizo dentro de las cámaras, las semillas se envolvieron en papel de estraza doblado a manera de sobre y se desinfectaron colocando los sobres en una solución de cloro al 5\% durante un minuto y a continuación fueron trasferidos a una solución de alcohol al 10\% durante 30 segundos, finalmente fueron enjuagados con agua hervida (Figura 2a).

Antes de colocar las semillas dentro de los frascos se agregó agua hervida al frasco desinfectado, dentro del ambiente estéril, cubriendo la base del cono de cartón a una altura aproximada de $1 \mathrm{~cm}$ a continuación, se abrieron los sobres de papel y se colocaron las semillas en la parte alta de los conos tomando con pinzas el papel invertido y tocando repetidamente la superficie del cartón como si estuviese espolvoreando (Figura 2b). Se prepararon un total de 39 frascos, utilizando semillas de tres diferentes especies (13 de cada una): Gongogra sp., Vanillan planifolia, Epidendrum sp., colectadas en los bosques de la región de Zacapoaxtla.
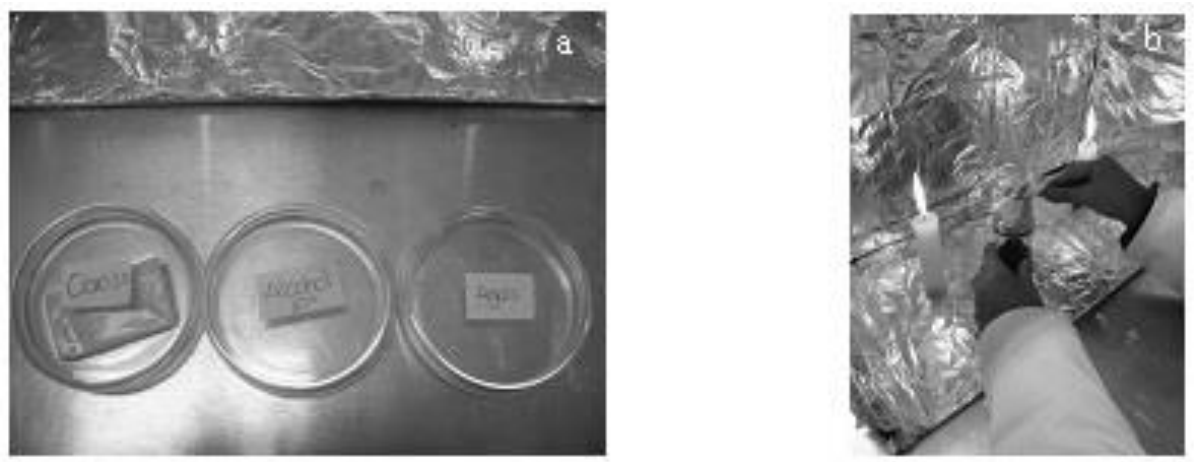

Figura 2. Procedimiento de desinfección de semillas previo a la siembra (a) y método de siembra (b).

Los frascos se expusieron a iluminación natural, con poca insolación y dentro de cajas de plástico para evitar contaminación con polvo. Se monitorearon, utilizando un microscopio estereoscópico, cambios en las semillas para detectar hinchazón o germinación. Las muestras se revisaron semanalmente, cuando el nivel del agua disminuyó se agregó agua hervida con jeringa estéril.

El procedimiento para la elaboración de los sistemas de germinación resultó sencillo y práctico, se contaminaron 13 frascos que fueron desechados. Hasta el momento únicamente se observó germinación en semillas de $V$. planifolia (Figura 3a) mientras que en Gongogra sp. Solamente se observaron semillas hinchadas (Figura 3b).
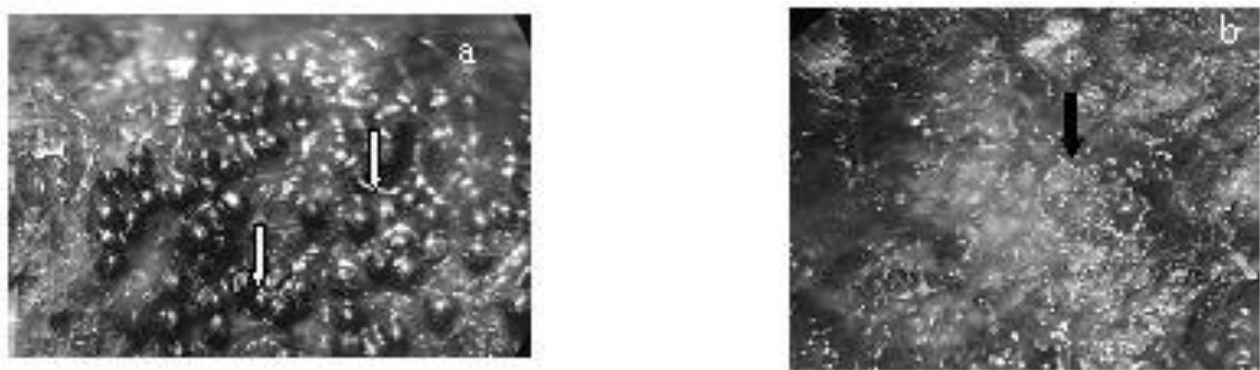

Figura 3. Semillas de Vanillan planifolia (a); y Gongogra sp. (b) después de 180 días de colocación en el sistema de germinación, observadas con microscopio estereoscópico a 4x. Las flechas blancas indican la expulsión, en las semillas, de tejido que se convertirá en raíces, la flecha negra señala las semillas. 
Se observó hinchamiento en todas las semillas; sin embargo, hasta el momento solo se ha detectado la expulsión de tejido que constituirá la raíz en tres de los 13 frascos en los que se colocaron semillas de $V$. planifolia. Las semillas germinadas se transfirieron a un medio de cultivo sintético para verificar su viabilidad, pero no se han conseguido transferir con éxito. Se cree que la transferencia se realizó de manera prematura, ocasionado que las plántulas no continuaran su crecimiento o bien se contaminaron. Hasta el momento no se tiene una estrategia funcional para la segunda etapa del cultivo.

Se han desarrollado estrategias para la germinación de semillas de orquídeas que incluyen la utilización de hongos simbiontes; sin embargo, aún no está claro cuál es la mejor manera de obtener resultados exitosos en diferentes condiciones de cultivo (Pereira et al., 2005; Otero et al., 2013; Mercado et al., 2020). Otero y Bayman (2009) señalan que la metodología más efectiva es en condiciones asimbióticas; no obstante, para este caso se considera que es necesaria la búsqueda de hongos asociados en plantas silvestres, que estimulen la germinación de semillas. Incluso hay estudios que señalan que un pretratamiento de las semillas permite incrementar los porcentajes de viabilidad y germinación en más de 90\% (Salazar Mercado et al., 2019)

Por otro lado, existe la posibilidad de utilizar productos orgánicos que sirvan como señales químicas (pulpa de plátano o agua de coco) cuyo contenido de azúcares, aminoácidos, antioxidantes, minerales, ácidos orgánicos, etc., promueven el crecimiento vegetal (Arditi, 1993; Moreno y Menchaca, 2007). Cheng et al. (2015) encontraron que la adición de sustancias facilita la germinación y el desarrollo del embrión, no obstante, se debe cuidar la concentración y el tiempo en que las semillas permanecen en contacto con dichas sustancias.

Tejeda-Sartorius et al. (2017) proponen que para cultivar orquídeas se debe elegir la especie correcta y generar condiciones ambientales específicas para desarrollarlas, de manera que se considera que los estudios ecofisiológicos de las plantas deben ser la base de las estrategias propuestas, teniendo presente la búsqueda de procedimientos accesibles que finalmente puedan ser reproducibles por las personas que se dedican al comercio de plantas de la familia Orquidaceae.

En necesario diseñar estrategias para la conservación de orquídeas en los bosques conservados de México, procurando un manejo sustentable y justo con los pobladores de los lugares (MartínezFeria, 2010) por lo que este trabajo tiene como fin desarrollar un procedimiento económico y de fácil acceso que sea redituable para los que se dedican al comercio de orquídeas, reduciendo así los impactos de la extracción ilegal de ejemplares.

\section{Conclusiones}

El sistema de germinación funciona en términos generales pero su eficiencia es baja, se considera que debe de buscarse un elemento adicional como el uso de diferentes hongos endófito, o bien aplicando extractos estimulantes (que contengan fitohormonas como el agua de coco). Es indispensable desarrollar estrategias que permitan el traslado de las semillas germinadas a un medio o sustrato que permita continuar con su desarrollo lograr el establecimiento de las plántulas. 


\section{Literatura citada}

Arditti, J. and Ghani, K. A. 2000. Numerical and physical properties of orchid seeds and their biological implications. New Phytol. 145(3):367-421.

Chen, Y.; Goodale, U. M.; Fan, X. L.; and Gao, J. Y. 2015. Asymbiotic seed germination and in vitro seedling development of Paphiopedilum spicerianum: an orchid with an extremely small population in China. Global Ecol. Conserv. 3:367-378. Doi: 10.1016/j.gecco.2015.01.002.

Damon, A. 2003. Las epífitas. Ecosistemas y comunidades: procesos naturales y sociales de los bosques. Ecofronteras. 18:17-20.

Emeterio-Lara, A.; Palma-Linares, V.; Vázquez-García, L. M. and Mejía-Carranza, J. 2016. Usos y comercialización de orquídeas silvestres en la región sur del estado de México. Polibotánica. 42:197-214.

Hágsater, E.; Soto-Arenas, M. A.; Salazar-Chávez, G. A.; Jiménez-Machorro, R.; López-Rosas, M. A.; Dressler and Robert L. 2005. Las orquídeas de México. Instituto chinoin. México, DF. 304 p.

Karol-Chávez, H.; Mosquera-Espinosa, A. T. and Otero-Ospina, J. T. 2015. In vitro propagation of Comparettia falcata Poepp and endl. (Orchidaceae) seeds using symbiotic and asymbiotic techniques. Acta Agron. 64(2):125-133.

Martínez-Feria, A. 2010. Patrones de distribución y áreas prioritarias para la conservación de las orquídeas en riesgo de Oaxaca. Tesis de Maestría. Centro interdisciplinario de investigación para el desarrollo integral regional unidad Oaxaca. $67 \mathrm{p}$.

Mercado, S. A. S.; Caleño, J. D. Q. and Rozo, L. Y. M. 2020. Improvement of the methodology of the tetrazolium test using different pretreatments in seeds of the genus epidendrum (Orchidaceae). J. Seed Sci. 42(e202042013): 1-8. http://dx.doi.org/10.1590/2317-1545v42231028.

Moreno, D. and Menchaca, R. A. 2007. Efecto de los compuestos orgánicos en la propagación in vitro de stanhopea tigrina bateman orchidaceae. Foresta Veracruzana. 9(2):27-32.

Otero, J. T. and Bayman, P. 2009. Symbiotic vs Asym-biotic seed germination in epiphytic orchids. Acta Agron. 58(4):270-276.

Otero, J. T.; Mosquera-Espinosa, A. T. and Flanagan, N. S. 2013. Tropical orchid mycorrhizae: potential applications in orchid conservation, comercialization, and beyond. In: fourth scientific conference on andean orchids. Lankesteriana. 13(1-2):57-63.

Pérez-Bravo, R.; Salazar-Gerardo, A. and Mora-Guzmán, E. 2010. Orquídeas de las lomas-la manzanilla, Sierra Madre Oriental, Puebla, México. Boletín de la Sociedad Botánica de México. 87:125-129.

Pradhan, S.; Regmi, T.; Ranjit, M. and Pant, B. 2016. Production of virus-free orchid cymbidium aloifolium (L.) Sw. by various tissue culture techniques. Heliyon. 2(10):e00176. http://dx.doi.org/10.1016/j.heliyon.2016.e00176.

Salazar-Mercado, S. A.; Botello-Delgado, E. A. and Quintero-Caleño, J. D. 2019. Pre-treatments effect on the tetrazolium test on epidendrum barbaricum hágsater and dodson seeds. Acta Agron. 68(4):306-311. Doi: 10.1590/2317- 1545v42231028.

Suzuki, R. M.; Moreira, V. C.; Pescador, R. and Melo, F. W. 2012. Asymbiotic seed germination and in vitro seedling development of the threatened orchid Hoffmannseggella cinnabarina. In vitro Cellular and Developmental Biology-Pant. 48(5):500-511 Doi: 10.1007/s11627012-9460-1.

Tejeda-Sartorius, O.; Téllez-Velasco, M. A. A. y Trejo-Téllez, L. I. 2017. Características ornamentales de orquídeas silvestres y su propagación con fines comerciales. Alternativa de aprovechamiento sustentable ex situ. Agroproductividad. 10(6):37-46. 